\title{
A study of gene expression changes at the $B p-2$ locus associated with bitter pit symptom expression in apple (Malus pumila).
}

\author{
Buti M' ${ }^{1}$, Sargent DJ ${ }^{1}$, Velasco $\mathbf{R}^{\mathbf{1}}$, Colgan $\mathbf{R J}^{\mathbf{2}}$ \\ ${ }^{1}$ Fondazione Edmund Mach, Centre for Research and Innovation, via Mach 1, San Michele all'Adige, \\ $38010(\mathrm{TN})$, Italy \\ ${ }^{2}$ Natural Resources Institute, University of Greenwich, Chatham, Kent ME4 4TB, UK
}

\begin{abstract}
Bitter pit is a physiological disorder of apples that develops in the latter stages of fruit development and during storage. It is characterized by localized necrotic cells that collapse and form pits in the epidermis and outer cortex of fruit. The disorder has been associated with low calcium concentrations, and poor calcium distribution within fruit. The mechanism that leads to individual cell necrosis, while surrounding cells remain healthy, is not fully understood. In order to ascertain the underlying process of bitter pit incidence in apple fruit, a mapping population of 'Braeburn' (susceptible to bitter pit) $\times$ 'Cameo' (resistant to bitter pit) was used to map the trait over two growing seasons. A subset of 96 genotypes from the mapping population representing the full range of phenotypes in the same ratio as the full population were selected for genotyping and functional characterization. RNA-Seq analysis on fruits samples of three resistant and three susceptible lines at seven developmental stages $(21,42$, $63,84,105,126$ and 147 days post fertilization) identified a number of candidate genes displaying differential gene expression. A subset of candidate genes selected based on their position within the identified QTL interval on chromosome 16 validated by RT-qPCR, and two candidate genes displaying differential gene expression were highlighted as strong candidates for the control of bitter pit symptom expression at the $B p-2$ locus.
\end{abstract}

\section{Introduction}

Bitter pit is the most important physiological disorder affecting apples (Ferguson and Watkins, 1989; Zupan et al., 2013): its main symptom is the manifestation of deep brown or black lesions or spots varying from 2 to $10 \mathrm{~mm}$ in diameter which disfigure the fruit flesh (Miqueloto et al., 2014). The 
location of pits is usually just below the skin but, in severe cases, the pits may extend throughout the cortex. They are generally concentrated at the calyx end of the fruit as small, water-soaked spots on the skin (Perring, 1985). This 'pitting' of the cortical flesh is caused by the breakdown of the cell plasma membranes, which then dry out and turn brown over time (Faust and Shear, 1968). Whilst the disorder initiates during fruit development on the tree, symptoms occasionally are not observed until fruit is stored post-harvest. Numerous studies have suggested a link between bitter pit susceptibility and relative fruit calcium content (Ferguson and Watkins, 1992; Korban and Swiader, 1984; Smock and Neubert, 1950; Volz et al., 2006), with various calcium application regimes having been proposed for the control of symptom expression. However, increasing fruit calcium by spray application is problematic, and its effectiveness is limited by the timing of spray application, the apple variety, the calcium status of the tree, and the degree of fruit shading and transpiration rates of the plants after application (Hewett and Watkins, 1991).

Moreover, $\mathrm{Ca}^{2+}$ transport within the plant is tightly controlled and, where transportation is disrupted, localized cellular deficiencies develop because $\mathrm{Ca}^{2+}$ cannot be mobilized from older tissues and redistributed via the phloem (White and Broadley, 2003). Calcium deficiencies can lead to localized cell death forming pits in the flesh of apples (White and Broadley, 2003) associated by increased plasma membrane leakage and cell plasmolysis (de Freitas and Mitcham, 2010). Calcium supply to fruit is dependent on transpiration water flow, and fruits compete increasingly with shoots and leaves as they develop. Delivery of calcium to fruits drops quickly after fruit set (Montanaro et al., 2015) and fruits rely on delivery of nutrients and sugars from the phloem (White, 2000). In addition, barriers to calcium flow exist during ripening at the peduncle, where the formation of insoluble calcium oxalate crystals decrease its movement into the fruit. Distribution of calcium in apple is channeled through the network of primary and secondary xylem and phloem vessels (Dražeta et al., 2004), and a decline in xylem functionality, particularly at the calyx end of the fruit, has been associated with a zone of increased bitter pit symptoms (Tomala and Soska, 2004). Additionally, the supply of nutrients can be disrupted in some varieties such as Braeburn, where rapid fruit expansion leads to crushing of the vascular tissue (Dražeta et al., 2004). Cell expansion during fruit development is driven by increases in cell turgor (Mathews, 2009), and calcium fluxes may contribute to changes in cell turgor pressure through the modification of ion channel activity (Konrad et al., 2011), causing an increase in cell volume during fruit development (Hocking et al., 2016; $\mathrm{Ng}$ et al., 2013). The epidermis and hyperdermis of apple are regions of the fruit that undergo rapid expansion during the latter stages of fruit development and these areas, along with the calyx, are most prone to bitter pit symptom development (Ferguson and Watkins, 1989). However, it is unknown whether stresses associated with 
cell expansion and turgor regulation during the latter stages of fruit development predispose tissue to bitter pit formation.

A complex interaction exists between the control of cell turgor and cell wall expansion (Hocking et al., 2016). Cell wall expansion is stimulated by increasing cell size and modification to cell wall architecture by the action of degrading enzymes that allow an increasing of cell wall elasticity, and which in turn accommodates enlarged cells during fruit development (Brummell, 2006; Ng et al., 2013). The cell wall is composed of a cellulose-xyloglucan network embedded in a matrix of pectic polysaccharides (Carpita and Gibeaut, 1993). Pectin is a major component of plant cell walls, but is mainly found within the middle lamella where it is primarily laid down as homogalacturonans, consisting of (1,4)- $\alpha$-linked galacturonans that are often methyl esterified (Ralet et al., 2001; Willats et al., 2001) when secreted into the cell wall. Calcium ions form ionic linkages between de-esterified homogalacturons in an 'egg-box' array (Morris et al., 1982; Tibbits et al., 1998). The availability of $\mathrm{Ca}^{2+}$ in the apoplast is influenced by the extent of de-esterification of homogalacturonans and the availability of calcium binding sites in the apoplast, which is regulated by the action of pectin methyl esterases (PME) (Brummell and Harpster, 2001). Free $\mathrm{Ca}^{2+}$ in the apoplast stabilizes membrane integrity and impacts on the $\mathrm{Ca}^{2+}$ concentration within the cytoplasm $\left(\left[\mathrm{Ca}^{2+}{ }_{\text {cyt }}\right]\right)$. Movement of $\mathrm{Ca}^{2+}$ across the plasma membrane and the tonoplast is tightly controlled: entry into plant cells is allowed by $\mathrm{Ca}^{2+}$ channels (White, 2000), while maintenance of a steady-state $\left[\mathrm{Ca}^{2+}\right.$ cyt] is regulated through Ca-ATPase and $\mathrm{Ca}^{2+} / \mathrm{H}^{+}$antiporters (White, 2000). Hormonal (gibberellins and auxins) and environmental cues lead to oscillations in $\left[\mathrm{Ca}^{2+}\right.$ cyt $]$ that are caused by an influx of calcium through cation channels in the plasma membrane, ER and tonoplast (Allen et al., 2001; White, 2000).

Whether or not the loss of membrane integrity initiates the onset of bitter pit formation is still to be determined. In grape, movement of solutes across the plasma membrane become less controlled during cell death, but membranes remain intact even after the loss of cell vitality (Caravia et al., 2015) suggesting that lack of ion selectivity, rather than loss of membrane integrity, could be involved in bitter pit symptom expression (Hocking et al., 2016). The genetic and physiological mechanisms underlying the disorder to date are poorly understood. Previously, a two-gene model ( $B p-1$ and $B p$ 2) for the genetic control of bitter pit was proposed (Buti et al., 2015; Korban and Swiader, 1984), and genetic studies identified a locus on LG16 of the apple genome that was associated with the control of bitter pit symptom expression, explaining up to $42.8 \%$ of the observed phenotypic variance (Buti et al., 2015; Kumar et al., 2013). In the study of Buti et al. (2015), the locus on LG16 was assigned as the $B p-2$ locus, and 137 genes were identified in the QTL region. However, none of them were proposed as likely candidates for the control of bitter pit symptom expression. 
In this investigation, a progeny of 1,266 seedlings from the cross 'Braeburn' (susceptible to bitter pit) × 'Cameo' (not susceptible to bitter pit) were phenotyped for bitter pit symptoms. A total of 94 progenies from the full population that displayed the same distribution of symptoms as the full progeny were selected, and the QTL for bitter pit on LG16 was confirmed in the progeny. RNA was extracted from fruits of three bitter pit susceptible and three bitter pit not susceptible seedlings at seven developmental stages (from 21 days post fertilization to fully mature fruits). RNA-Seq was performed on pooled RNA samples of susceptible plants stage 1, susceptible plants stage 7, not susceptible plants stage 1 and not susceptible plants stage 7. Genes from the LG16 QTL region that were identified as being differentially expressed between the four RNA-Seq samples were validated by RT-qPCR in all seven developmental stages from the three susceptible and three not susceptible samples performed individually. Candidate genes were identified, and a potential model for the genetic and physiological control of bitter pit symptoms expression is proposed.

\section{Materials and methods}

\section{Plant Material, DNA extraction and bitter pit severity phenotypic evaluation}

The cross 'Braeburn' (susceptible to bitter pit) $\times$ 'Cameo' (resistant to bitter pit) $(\mathrm{B} \times \mathrm{C})$ was performed at Fondazione Edmund Mach (FEM) in 2004. A total of 1,266 seedlings were raised, grafted onto 'M.9' rootstocks and maintained following standard technical management procedures in a field environment at Spini di Gardolo in Trentino, Italy. The entire $\mathrm{B} \times \mathrm{C}$ progeny were phenotyped for bitter pit symptoms over three successive growing seasons between 2012 and 2014 following the scoring system described in Buti et al. (2015). Briefly, the bitter pit susceptibility of each seedling carrying fruits was scored by eye at full fruit maturity. Symptoms were scored on a five-point scale: from no symptoms (0) through to very severe symptoms (4). The visual scale of Buti et al. (2015) is shown in Supplementary Figure S1. From the full progeny, 94 seedlings that displayed the full distribution of bitter pit severity symptoms in a ratio that closely matched the full progeny were selected for genotyping and functional characterization. Newly emerging, unexpanded leaves were collected in the spring, freeze-dried within $2 \mathrm{~h}$ and ground to a powder using a MM 300 Mixer Mill (Retsch Inc). DNA was extracted using the CTAB extraction method described by Chen and Ronald (1999). The resultant DNA was quantified using a NanoDrop 8000 spectrophotometer (Thermo Scientific) and diluted to $10 \mathrm{ng} / \mathrm{ul}$ for use in PCR. 
Microsatellite marker screening and linkage map construction

A total of 95 SSRs distributed throughout the 17 linkage groups of published Malus linkage maps (Fernández-Fernández et al., 2008; Silfverberg-Dilworth et al., 2006; Velasco et al., 2010) were selected for testing in the parental genotypes of the $\mathrm{B} \times \mathrm{C}$ mapping population. Fluorescent PCR was performed following the procedures described by Sargent et al. (2012), initially in simplex in the parental genotypes to determine marker amplicon sizes and heterozygosity, and subsequently in multiplex for polymorphic markers scoring in 94 seedlings of the $\mathrm{B} \times \mathrm{C}$ population. Products were electrophoresed through an ABI 3730x Genetic Analyzer (Life Technologies), following which data were analyzed and scored using the GeneMapper (Life Technologies) software application. The resultant segregation data were scrutinized by eye to identify scoring errors. Segregation data for the heterozygous SSR markers identified were used to construct a $\mathrm{B} \times \mathrm{C}$ linkage map using JOINMAP 4.1 (Kyazma, NL) (Van Ooijen, 2006) implementing regression mapping. Marker placement was determined using a minimum LOD score threshold of 3.0, a recombination fraction threshold of 0.35 , ripple value of 1.0, jump threshold of 3.0 and a triplet threshold of 5.0, and mapping distances were calculated applying the Kosambi mapping function. Linkage maps were plotted using MAPCHART 2.2 (Voorrips, 2002) with linkage group nomenclature following that of previous apple linkage maps (i.e., Fernández-Fernández et al., 2012).

\section{Identification of bitter pit QTL}

Quantitative trait loci analysis was performed using bitter pit severity data for the 94 genotyped progeny. Data from each individual year's evaluation were used as traits, and analyzed with interval mapping, using MapQTL 6.0 (Kyazma, NL) (Van Ooijen, 2009). A genome-wide LOD threshold of 2.7 was determined following a permutation test running 20,000 permutations for each year data. The restricted multiple QTL method (rMQM) was performed using markers with significant association with incidence of bitter pit as co-factors to attempt uncover the presence of minor QTL throughout the linkage groups of the genetic map. The step size for both IM and rMQM was $1.0 \mathrm{cM}$.

\section{Additional marker analysis}

Following the identification of a significant QTL on LG16 of the B $\times$ C linkage map, corresponding genomic region was saturated with additional SSR markers chosen from published apple genetic maps (Buti et al., 2015; Fernández-Fernández et al., 2008; Silfverberg-Dilworth et al., 2006; Velasco et al., 2010) scored following the procedures detailed above. Additionally, three SNP markers previously 
shown to locate to the proximal end of LG16 (Buti et al., 2015; Kumar et al., 2013) were scored in the $\mathrm{B} \times \mathrm{C}$ mapping progeny using novel primer pairs following the methods described in Padmarasu et al. (2014). Mapping and subsequent QTL analysis using the additional markers followed the methods described above.

\section{RNA extraction and pooling}

Total RNA was extracted from the peel of fruits from three susceptible and three non-susceptible seedlings (susceptible seedlings 592, 921, 1210; non-susceptible seedlings 2, 4 and 8) from seven developmental stages taken at regular intervals from post fertilization to fully mature fruits. Starting from day 21 after fertilization, total RNA was extracted every 21 days $(21,42,63,84,105,126$ and 147 days post fertilization). From each sample, $50 \mathrm{mg}$ of apple peel were used to extract total RNA using the Spectrum ${ }^{\mathrm{TM}}$ Plant Total RNA Kit (Sigma-Aldrich) with the addition of an on-column DNAase treatment (Sigma-Aldrich). The extraction method followed the manufacturer's instructions with two modifications; 1\% PVP was added to lysis solution and the number of washings was doubled, meaning two washings with wash solution 1 and four washings with wash solution 2 were performed per extraction. The extracted total RNA was diluted in $50 \mu 1$ of elution solution for each sample. The quality and quantity of the extracted RNA was assessed using a NanoDrop spectrophotometer (Thermo Scientific) and an Agilent 2100 BioAnalyzer with the Agilent RNA 6000 Nano Kit. Total RNA samples were considered suitable for RNA-Seq analysis when their concentration was greater than $50 \mathrm{ng} / \mu \mathrm{l}, 260 / 280$ and 260/230 ratios were above 1.8 and 2.0, respectively, and the RIN (RNA integrity number) was above 7.00. Four RNA pools were prepared for RNA-Seq analysis: total RNAs from the three susceptible and resistant plants were pooled from the first and seventh stages of fruit development individually to yield (a) stage 1 susceptible pool, (b) stage 7 susceptible pool, (c) stage 1 resistant pool, and (d) stage 7 resistant pool. Each RNA pool was obtained by combining the same quantity of RNA from each extracted sample.

\section{RNA sequencing and mapping}

A total of $2 \mu \mathrm{g}$ of RNA per pool was used for RNA-Seq library construction. Libraries were prepared using the TruSeq RNA sample preparation kit (Illumina), indexed, multiplexed and sequenced using $101 \mathrm{bp}$ single-end sequencing on a single lane of a HiSeq 2000 sequencer (Illumina) at the Genomic Resources Core Facility of the Weill Medical College, Cornell University, USA. The quality of the raw reads was determined using the FastQC software application (Andrews, 2010). The four RNA 
read sets were mapped individually to the Malus_x_domestica.v1.0.consensus_CDS.fa (Mxdv1) transcriptome (Velasco et al., 2010) using Bowtie2 (Langmead and Salzberg, 2012) with default settings.

\section{Differential expression analysis}

For each of the four RNA read sets, the number of reads mapping to each Mxdv1 predicted gene was calculated from the Bowtie2 .sam alignments using simple bash commands. Differential gene expression analysis based on the negative binomial distribution was carried out using Bioconductor DESeq (Anders and Huber, 2010). Transcription levels were normalized, and the variation between expressed genes was determined between pools (a) and (c) and pools (b) and (d) (susceptible pool stage $1 v s$. resistant pool stage 1; susceptible pool stage $7 v s$. resistant pool stage 7). Genes were considered as differentially expressed when their $\log _{2} \mathrm{FC}$ value (the logarithm of fold change value of the expression of the same gene) between the compared pools was greater than 3 or lower than -3 .

\section{Candidate gene verification by $R T-q P C R$}

Genes located in the first four megabases $(\mathrm{Mb})$ of chromosome 16 of the apple genome sequence (Velasco et al., 2010) (where major QTL for bitter pit resistance is located) were identified and scrutinized for differential expression. Differentially expressed genes were annotated using Blast2GO (Conesa and Götz, 2008) against the non-redundant NCBI database using an e-value cut-off of $10^{-3}$. Expression of candidate genes was validated through RT-qPCR on individual RNA samples. Genespecific primers for quantitative PCR were designed using Primer3 (Untergasser et al. 2012; http://bioinfo.ut.ee/primer3-0.4.0/) adopting the following design criteria: a minimum size of $18 \mathrm{bp}$, maximum $24 \mathrm{bp}$, optimum $20 \mathrm{bp}$; a minimum $\mathrm{Tm}$ of $58^{\circ} \mathrm{C}$, maximum $63^{\circ} \mathrm{C}$, optimum $60^{\circ} \mathrm{C}$; a product size between $80 \mathrm{bp}$ and $140 \mathrm{bp}$, (optimum $110 \mathrm{bp}$ ); a maximum self complementarity = 3; and a maximum 3' self complementarity $=2$. The designed primer pairs are reported in Table 2 .

A total of $1 \mu \mathrm{g}$ of total RNA from each of the 7 fruit developmental stage of three resistant and three susceptible genotypes was used as a template to synthetize cDNAs using the Invitrogen SuperScript ${ }^{\circledR}$ VILO kit following the manufacturers' instructions. Md8283 was employed as a housekeeping gene (Botton et al., 2011; Longhi et al., 2012) and three technical replicates for each sample were performed. Quantitative PCR was performed on a ViiA7 RT-qPCR machine (Life Technologies, Carlsbad, CA, USA) in a final volume of $12.5 \mu \mathrm{l}$ containing $2 \mu \mathrm{l}$ of cDNA, $0.20 \mu \mathrm{l}$ of each primer (10 $\mu \mathrm{M}$ dilution), $6.25 \mu 1$ of FAST SYBR GREEN master mix (Life Technologies, Carlsbad, CA, 
USA) and $3.85 \mu \mathrm{l}$ of sterile $\mathrm{H}_{2} \mathrm{O}$. The RT-qPCR cycling conditions were: $95^{\circ} \mathrm{C}$ for $20 \mathrm{~s}$, followed by 40 cycles of $95^{\circ} \mathrm{C}$ for $1 \mathrm{~s}$ and $60^{\circ} \mathrm{C}$ for $20 \mathrm{~s}$. A final amplification cycle of $95^{\circ} \mathrm{C}$ for $15 \mathrm{~s}, 60^{\circ} \mathrm{C}$ for 1 min and $95^{\circ} \mathrm{C}$ for $15 \mathrm{~s}$ was performed to determine the melting curve. The $\Delta \Delta \mathrm{Ct}$ method was used to plot the relative gene expression as mean of the normalized expression values of the replicates (Livak and Schmittgen, 2001).

\section{Results}

Bitter pit severity distribution in the $B \times C$ mapping population

Bitter pit severity symptoms were scored in the $\mathrm{B} \times \mathrm{C}$ mapping population over growing seasons in 2012 and 2014. In total, $20.6 \%$ and $37.7 \%$ of trees did not bear fruit in 2012 and 2014 respectively. The remaining trees were classified on a scale of $0-4$ depending on the severity of the symptoms observed. Distribution of symptoms vs. no symptoms was 456 vs. 549 (chi-squared = 8.61; 261 no fruits) in 2012, and 262 vs. 527 (chi-squared $=89.01 ; 477$ no fruits) in 2014. The number of trees grouped into each of the five classes in each year of evaluation is shown in Figure 1. The 94 plants selected from the full $\mathrm{B} \times \mathrm{C}$ mapping population for genotyping follow the 2012 whole population phenotypic distribution: 51 plants with phenotype 0 in 2012, 19 with phenotype 1, 12 with phenotype 2, 9 with phenotype 3 and 3 with phenotype 4 were selected. Six plants were selected for RNA-Seq analysis from the 94 genotyped plants of the $\mathrm{B} \times \mathrm{C}$ subpopulation. The three selected resistant plants (genotypes 2, 4 and 8) did not display any bitter pit symptoms over the two years of evaluation. Since three plants that displayed a severity symptom score of 4 in both years of evaluation were not available, the three plants that displayed the most severe symptoms throughout the phenotyping period were selected: genotypes 592 and 1210 were scored as 4 in both years, whilst genotype 921 was scored as 4 in 2012 and 3 in 2014.

\section{Linkage map construction and QTL analysis}

Eighty four of the 95 initially selected SSR markers segregated, and were mapped in the $\mathrm{B} \times \mathrm{C}$ progeny (genotypes reported in Supplementary File 1). The linkage map spanned a total of $822.44 \mathrm{cM}$ across the 17 linkage groups (Supplementary Figure 2). The performed QTL analysis revealed a major QTL on LG16 of the $\mathrm{B} \times \mathrm{C}$ linkage map, with the peak of the LOD in a $0.98 \mathrm{cM}$ interval. This genomic region was saturated with additional five SSR and three SNP markers mapping to the proximal end of LG16: these markers were scored in the $\mathrm{B} \times \mathrm{C}$ progeny, and a new QTL analysis on LG16 only was carried out. As shown on Figure 2, the QTL on LG16 contains markers CH02a03, NZ_SNP1_C, 
Hi22f06 and QTL16_SNP02. The QTL explained 24.8\% of the total variance in 2012 and $27.8 \%$ of the total variance in 2014, with an associated LOD of 5.81 and 4.52, respectively, most closely associated with marker NZ_SNP1_C in 2012 and markers NZ_SNP1_C, Hi22f06 and QTL16_SNP02 in 2014 (Figure 2). The region in which the QTL was identified spanned a total of $0.9 \mathrm{Mbp}$, from marker $\mathrm{HiO} 2 \mathrm{H} 08$ to $\mathrm{CH} 05 \mathrm{c06}$. A second QTL with a LOD value of 3.22 (explaining $14.6 \%$ of the observed variance) was detected on LG03 only for 2012, with the LOD peak associated with Hi04c10 marker. The genotyping results for all the markers used in this experiment are reported on the Supplementary File S1.

\section{RNA-Seq and candidate gene expression identification}

A total of 185.5 million 101-bps single-end reads were produced in total from the sequencing of the four multiplexed libraries on one lane of an Illumina flow cell, with the total number of reads produced from each individual library ranging from 43 to 51 millions (Table 1). RNA-Seq reads have been deposited in the ArrayExpress database at EMBL-EBI (www.ebi.ac.uk/arrayexpress) under accession number E-MTAB-6190. Reads from the four RNA pools were mapped to the Malus_x_domestica.v1.0.consensus gene models, with a percentage of reads from each library mapping to the gene models ranging from $67.1 \%$ to $68.4 \%$. From the RNA-Seq dataset, 4,213 genes were differentially expressed between resistant and susceptible samples in the first stage of development, whilst 5,050 were differentially expressed between resistant and susceptible samples at developmental stage 7 (Supplementary Files S2). Within the initial 4 Mb of LG16, where the major bitter pit QTL was identified, 22 genes resulted to be differentially expressed. However, after annotation, these 22 predicted genes were shown to represent 13 genes only (Table 2).

\section{Candidate gene expression validation}

The 13 candidate genes identified as differentially expressed in the LG16 QTL region were validated in developmental stages 1 and 7 by RT-qPCR. Of the 13, five genes did not show significantly different expression levels between the two developmental stages and between susceptible and nonsusceptible genotypes (Figure 3). Of the remaining, genes MDP0000186069 (cysteine endopeptidase), MDP0000199110 (DNA binding) and MDP0000161881 (transcription factor) were more expressed in developmental stage 7 in susceptible plants, whilst no significant differences were observed between stages 1 and 7 in non-susceptible plants. Genes MDP0000376284 (transcription repressor activity) and MDP0000263725 (kinase activity) were more expressed in non-susceptible 
plants than in the susceptible plants in both developmental stages. MDP0000177891 (O-glycosyl hydrolase) was more expressed in the first developmental stage in both susceptible and nonsusceptible plants; MDP0000300083 (glycosyl transferase) was more expressed in developmental stage 7 in the non-susceptible plants, whilst no significant differences in expression were observed between stages 1 and 7 in susceptible plants. Finally, MDP0000071852 (plant lipid transfer) was more expressed in stage 1 than stage 7 in non-susceptible plants, but no significant differences were observed in expression between stages 1 and 7 in susceptible plants (Figure 3). For those genes where differential expression was observed between stages 1 and 7 in either resistant or susceptible plants (MDP0000161881, MDP0000300083, MDP0000186069, and MDP0000199110), gene expression was further investigated in all seven developmental stages using RT-qPCR. Gene expression for MDP0000161881 increased in susceptible plants in stage 4, reaching its highest levels of expression in stages 6 and 7. Expression of MDP0000300083 gene incrementally increased from stage 1 to stage 7 in resistant plants; gene expression for MDP0000186069 increased incrementally between stages 5 and 7 in susceptible plants; whilst gene expression for MDP0000199110 increased only at stage 7 in susceptible plants (Figure 4).

\section{Discussion}

In this investigation, RNA-Seq and subsequent RT-qPCR validation was implemented to study gene expression changes between apple genotypes classified as susceptible or non-susceptible (i.e. not expressing symptoms in campa) to bitter pit. Genetic analysis of the $\mathrm{B} \times \mathrm{C}$ segregating population revealed a single major significant QTL for bitter pit in the two years in which the progeny was phenotyped, and this QTL corresponded to the major locus associated with bitter pit in previous genetic studies (Buti et al., 2015; Kumar et al., 2013). In the study of Kumar et al. (2013), bitter pit susceptibility was most strongly associated with SNP ss475883359 from the apple 9k genotyping array (Chagné et al., 2012), which was converted to a PCR-based marker in this investigation and also shown to be most strongly associated with bitter pit susceptibility in the $\mathrm{B} \times \mathrm{C}$ segregating population.

The RNA-Seq analysis performed here revealed a number of genes differentially expressed across the seven developmental stages studied, and between susceptible and non-susceptible genotypes. Within the QTL region of LG16, a total of 13 genes were differentially expressed and were considered candidates for bitter pit susceptibility in apple and, according to their predicted function, two of these were considered as strong candidates. Bitter pit symptoms start as leaky cell membranes that progress 
to cell plasmolysis and membrane breakdown followed by cell wall collapse after cell death, leaving characteristic pithy lesions (Ferguson and Watkins, 1992; Fidler et al., 1973).

Numerous mechanisms contributing to bitter pit have been proposed, although a localised lack of calcium has long been suggested as the primary driver of bitter pit symptom expression (Fidler et al, 1973), with claims that calcium concentration in the peel is more closely related to the incidence of bitter pit than the concentration of calcium in either the core or flesh (Drake et al., 1966). At a localized level, regulation of calcium within the cell wall, plasma membrane, cytoplasm and vacuole affects the propensity for localized cell necrosis (de Freitas et al., 2013). Calcium contributes to cellular structure and function (Poovaiah and Leopold, 1973) by binding to membrane bound phospholipids and proteins (Hirschi, 2004). Maintaining a concentration of free calcium above 0.1 $\mathrm{mM} \mathrm{Ca}{ }^{2+}$ in the apoplastic pool has been reported to maintain plasma membrane structure and function (Plieth, 2001) and delay the onset of senescence (de Freitas et al., 2013). In contrast, cytosolic calcium $\left(\left[\mathrm{Ca}^{2+}\right]_{\text {cyt }}\right)$ is highly regulated, with concentrations maintained at 0.1-0.2 $\mu \mathrm{m}$, through the activity of $\mathrm{Ca}-\mathrm{ATPase}$ and $\mathrm{Ca}^{2+} / \mathrm{H}^{+}$antiporters located in the cell membrane (White, 2000). Vacuolar $\left[\mathrm{Ca}^{2+}\right]$ is maintained at 1-10 mM concentrations (Berridge 1997, White and Broadley 2003), and the steep gradient between the calcium concentration in the vacuole and cytoplasm is maintained by proton-cation exchange. Release of calcium from the vacuole through calcium channels plays a crucial role in calcium influx into the cytoplasm and leads to oscillations in the $\left[\mathrm{Ca}^{2+}\right]_{\text {cyt. }}$ The magnitude of these spatio-temporal oscillations are controlled by calcium efflux mechanisms (Allen et al., 2001).

In this study, genotypes classed as 'non-susceptible' to bitter pit had a higher gene expression profile of the ATP binding factor MDP0000263725 that favours the synthesis of Ins $(3,4,5,6) \mathrm{P} 4$ than those that were susceptible to bitter pit, suggesting that a reduction in its expression may be responsible for an increase in bitter pit symptom expression in susceptible apple genotypes. The rate at which calcium is released into the cytosol is regulated by the inositol phosphate family of signalling molecules (Berridge, 1997) which undergo a number of complex interconversion pathways. Inositol, 1,4,5 triphosphate (IP3), binds to vacuolar and non-vacuolar bound IP3 receptors (IPR3) that act as calcium ion channels (Berridge, 1997; Berridge et al., 2000), releasing calcium into the cytoplasm, while reducing inward conductance of $\mathrm{K}^{+}$ions (Gilroy et al., 1990). Inositol, 1,4,5 triphosphate (IP3) acts as an intermediary for the synthesis of a number of other inositol phosphate family members that have a role in calcium and cell turgor regulation. These include myo-inositol $(1,3,4,5,6)$ tetraphosphate (P5) which acts as an intermediate within the pathway and is interconverted to D myo Inositol 3,4,5,6 tetrakisphosphate $(\operatorname{Ins}(3,4,5,6) \mathrm{P} 4)$ by the action of a single enzyme $(1,3,4,5,6) \mathrm{P} 51$ - phosphatase (Ho 
and Shears, 2002). The interconversion of Ins $(1,3,4,5,6) \mathrm{P} 5$ to $\operatorname{Ins}(3,4,5,6) \mathrm{P} 4$ is possible as the enzyme can function as a phosphatase and kinase: the change in functionality is regulated by the ratio of available ATP/ADP (Ho and Shears, 2002). Ins(3,4,5,6)P4 has a biphasic (activation/inhibition) effect on $\mathrm{Ca}^{2+}$-activated chloride channels (CACCs; Mitchell et al., 2008) and in particular the CIC3 calcium channel which catalyses the selective flow of chloride ions across the membrane. Ins(3,4,5,6)P4 main effect on CACCs is inhibitory (Mitchell et al., 2008), preventing calcium dependent $\mathrm{Cl}^{-}$secretion from the vacuole and thus influencing plants ability to control cell turgor.

The sensitivity of CACCs to Ins $(3,4,5,6) \mathrm{P} 4$ increases in the presence of elevated $\left[\mathrm{Ca} 2^{+}\right.$cyt $]$as activation of CACC through phosphorylation is catalysed by the action of a $\mathrm{Ca}_{2}^{+}$dependant calmodulin kinase II (CaMKII) (Ho et al., 2001). The biphasic nature of Ins(3,4,5,6)P4 on CACCs makes it difficult to pin-point precisely the role of $\operatorname{Ins}(3,4,5,6) \mathrm{P} 4$ and reduced chloride secretion has on reducing susceptibility to bitter pit. However, a reduction in chloride secretion in mammalian cells caused by the inhibition of CIC-3 chloride channels using thapsigargin (T9) reduced cell proliferation and increased apoptosis (Zhang et al., 2006). The studies in mammalian cells suggests control of $\mathrm{Cl}^{-}$ movement across endomembranes is an important factor in preventing localised cell death, and as such, we hypothesis a similar mechanism may operate in apple fruit, and thus disruption of the synthesis of Ins $(3,4,5,6) \mathrm{P} 4$ could lead to an increase in bitter pit symptom expression.

Resistance to bitter pit development may also be a function of increased cell wall elasticity during fruit development. An increase in cell turgor drives cell enlargement mediated by the relaxation of the cell wall through changes in the viscoelastic properties of the cell wall matrix allowing cellulose microfibrils to rearrange or move apart (Allard et al., 2010; Zhang et al., 2011). Cell walls control their extensibility (cell wall creep) by the action of expansins, endoglucanases, xyloglucanendotransglycosylase/hydrolase (XTH), and pectin methylesterases (Cosgrove, 2016; Franková and Fry, 2013). In this investigation an additional candidate gene that may have a central role in modifying cell wall architecture was identified at the $B p-2$ locus. Transcript abundance of MDP0000300083, encoding the glycosyl transferase gene galactosidase 2 -alpha-Lfucosyltransferase was higher in non-susceptible lines sampled at the end of fruit development, and there was a steady rate of increase in transcription with advancing fruit development. Galactosidase 2 -alpha-L-fucosyltransferase has been reported to catalyse the incorporation of fucosyl residues into the side chains of xyloglucan $(\mathrm{XyG})$ molecules. $\mathrm{XyG}$ is a major hemicellulosic polysaccharide in the primary walls of dicots (Gullfot et al., 2009) which tethers cellulose microfibrils in an interconnected network surrounded by a pectin matrix (Carpita and Gibeaut, 1993; Cosgrove, 2005). The XyG backbone is composed of 1,4-linked $\beta$-D-Glcp residues, up to $75 \%$ of which are substituted with 
mono-, di-, or triglycosyl side chains (xylosyl, galactosyl, fucosyl or acetyl residues) (Hoffman et al., 2005; Peña et al., 2008; Schultink et al., 2014). The high degree of fucosylation of XyG observed in tissues undergoing rapid expansion e.g. pollen tubes (Lampugnani et al., 2013) and root epidermal cells (Liu et al., 2015; Obel et al., 2009) suggests the rates of fucosylation in cell walls increases when undergoing rapid expansion. The increased activity of Galactosidase 2 -alpha-L-fucosyltransferase during development in non-susceptible apple lines suggests a role for the gene in increasing cell wall elasticity, enabling the fruit to accommodate rapid turgor driven cell expansion during the latter stages of fruit development. Conversely, in bitter pit susceptible lines, an inability to respond in this way to cell expansion during fruit development could lead to a higher incidence of bitter pit symptom expression.

In this investigation, we studied the differential expression of genes within the bitter pit QTL region identified on LG16 of the apple genome in susceptible and non-susceptible genotypes. Following confirmation that the major QTL was present in the $\mathrm{B} \times \mathrm{C}$ mapping population, we undertook to characterize gene expression through RNA-Seq and validate the findings through RT-qPCR. A set of 13 differentially expressed candidate genes were identified of which MDP0000263725 and MDP0000300083 were strong candidates for the control of bitter pit symptom expression between susceptible and non-susceptible genotypes in the population. The two interrelated but independent processes described here that are potentially controlled by genes displaying differential gene expression between non-susceptible and susceptible lines in this investigation may contribute to an increase the incidence of bitter pit in susceptible apple genotypes. The data presented here have shed light on the possible genetic control of bitter pit symptom expression. In order to understand the role of the differentially expressed candidate genes MDP0000263725 and MDP0000300083, further work, investigating additional genotypes displaying differential bitter pit symptoms, as well as functional characterisation of the candidate genes using genetic transformation, and a detailed analysis of physiological changes associated with changes in their expression will be required.

\section{Acknowledgements}

The work was funded by a grant from the Autonomous Province of Trento to the Dipartimento di Genomica e Biologia delle Piante da Frutto of the Fondazione Edmund Mach, Trentino, Italy. 


\section{Competing interest statement}

The authors declare no conflicts of interest.

\section{Figure and Supplementary Material legends}

Figure 1 - Phenotypic distribution of bitter pit symptoms severity in the 'Braeburn' $\times$ 'Cameo' mapping population over the course of two growing seasons (2012 and 2014). Fruiting trees were classified on a $0-4$ scale depending on the severity of the symptoms observed. The number of plants grouped into each of the five classes is shown for each year of evaluation.

Figure 2 - Linkage group 16 of a subset $(n=94)$ of the $B \times C$ mapping population showing the positions of mapped markers along the linkage group in cM. Results of the QTL analysis using interval mapping of bitter pit symptom expression for 2012 and 2014 are reported.

Figure 3-RT-qPCR validation results for fruits at developmental stages 1 and 7 of the 13 candidate genes identified as differentially expressed in the LG16 QTL. Results for plants resistant to bitter pit (plant IDs: 2, 4, 8) were reported in blue (light for stage 1, dark for stage 7), while results for susceptible plants (plant IDs: 592, 921, 1021) were reported in red (light for stage 1, dark for stage 7). For each graph, title reports the gene ID and, in parentheses, an abbreviation expressing its function.

Figure 4 - RT-qPCR results for fruits at developmental stages 1 to 7 of the 4 genes here differential expression was observed between stages 1 and 7 in resistant plants for MDP0000300083 gene (Glycosyl transferase), and in susceptible plants for genes MDP0000161881 (Transcription factor), MDP0000199110 ( DNA binding) and MDP0000186069 (Cysteine endopeptidase). For each graph, title reports the gene ID and, an abbreviation expressing its function (in parentheses) and the phenotype of the plants on which the RT-qPCR experiment was conducted

Supplementary Figure S1 - Apple fruits at full maturity displaying different levels of bitter pit symptoms. Symptoms were scored on a five-point scale: no symptoms (0), low symptoms (1), medium symptoms (2), high symptoms (3) and very high symptoms (4). Pictures of fruits (whole and horizontal section) belonging to each scale point were reported. 
Supplementary Figure S2 - Initial linkage map and QTL analysis using interval mapping for a subset of 94 progenies of $\mathrm{B} \times \mathrm{C}$ mapping population. Marker positions are given in $\mathrm{cM}$ and accompanying graphs give LOD scores associated with bitter pit symptom expression for 2012 and 2014.

Supplementary File S1 - Genotyping results on a subset $(n=94)$ of the $B \times C$ mapping population. The position of each marker across respective linkage group was given, along with its segregation type and phase.

Supplementary File S2 - Results of DE analysis between resistant and susceptible samples in the first and seventh developmental stages. Only results for differentially expressed genes were reported.

\section{References}

Allard, J. F., Ambrose, J. C., Wasteneys, G. O., and Cytrynbaum, E. N. (2010). A Mechanochemical Model Explains Interactions between Cortical Microtubules in Plants. Biophys. J. 99, 10821090. doi:10.1016/j.bpj.2010.05.037.

Allen, G. J., Chu, S. P., Harrington, C. L., Schumacher, K., Hoffmann, T., Tang, Y. Y., et al. (2001). A defined range of guard cell calcium oscillation parameters encodes stomatal movements. Nature 411, 1053-7. doi:10.1038/35082575.

Anders, S., and Huber, W. (2010). Differential expression analysis for sequence count data. Genome Biol. 11, 1-12. doi:10.1186/gb-2010-11-10-r106.

Andrews, S. (2010). Babraham Bioinformatics - FastQC A Quality Control tool for High Throughput Sequence Data. Available at: http://www.bioinformatics.babraham.ac.uk/projects/fastqc/.

Berridge, M. J. (1997). Elementary and global aspects of calcium signalling. J. Physiol. 499 ( Pt 2), 291-306. Available at: http://www.ncbi.nlm.nih.gov/pubmed/9080360 [Accessed October 4, 2017].

Berridge, M. J., Lipp, P., and Bootman, M. D. (2000). The versatility and universality of calcium signalling. Nat. Rev. Mol. Cell Biol. 1, 11-21. doi:10.1038/35036035.

Botton, A., Eccher, G., Forcato, C., Ferrarini, A., Begheldo, M., Zermiani, M., et al. (2011). Signaling Pathways Mediating the Induction of Apple Fruitlet Abscission. Plant Physiol. 155, 185-208. doi:10.1104/pp.110.165779.

Brummell, D. A. (2006). Cell wall disassembly in ripening fruit. Funct. Plant Biol. 33, 103-119. doi:10.1071/FP05234. 
Brummell, D. A., and Harpster, M. H. (2001). Cell wall metabolism in fruit softening and quality and its manipulation in transgenic plants. Plant Mol. Biol. 47, 311-339. doi:10.1023/A:1010656104304.

Buti, M., Poles, L., Caset, D., Magnago, P., Fernandez Fernandez, F., Colgan, R. J., et al. (2015). Identification and validation of a QTL influencing bitter pit symptoms in apple (Malus $\times$ domestica). Mol. Breed. 35. doi:10.1007/s11032-015-0258-9.

Caravia, L., Collins, C., and Tyerman, S. D. (2015). Electrical impedance of Shiraz berries correlates with decreasing cell vitality during ripening. Aust. J. Grape Wine Res. 21, 430-438. doi:10.1111/ajgw.12157.

Carpita, N. C., and Gibeaut, D. M. (1993). Structural models of primary cell walls in flowering plants: consistency of molecular structure with the physical properties of the walls during growth. Plant J. 3, 1-30. doi:10.1111/j.1365-313X.1993.tb00007.x.

Chagné, D., Crowhurst, R. N., Troggio, M., Davey, M. W., Gilmore, B., Lawley, C., et al. (2012). Genome-Wide SNP Detection, Validation, and Development of an 8K SNP Array for Apple. PLoS One 7, e31745. doi:10.1371/journal.pone.0031745.

Chen, D.-H., and Ronald, P. C. (1999). A Rapid DNA Minipreparation Method Suitable for AFLP and Other PCR Applications. Plant Mol. Biol. Report. 17, 53-57. doi:10.1023/A:1007585532036.

Conesa, A., and Götz, S. (2008). Blast2GO: A comprehensive suite for functional analysis in plant genomics. Int. J. Plant Genomics 2008, 619832. doi:10.1155/2008/619832.

Cosgrove, D. J. (2005). Growth of the plant cell wall. Nat. Rev. Mol. Cell Biol. 6, 850-861. doi:10.1038/nrm1746.

Cosgrove, D. J. (2016). Catalysts of plant cell wall loosening. F1000Research 5, 1-13. doi:10.12688/f1000research.7180.1.

De Freitas, S. T., Amarante, C. V. T. d., Dandekar, A. M., and Mitcham, E. J. (2013). Shading affects flesh calcium uptake and concentration, bitter pit incidence and other fruit traits in "Greensleeves" apple. Sci. Hortic. (Amsterdam). 161, 266-272. doi:10.1016/j.scienta.2013.07.019.

De Freitas, S. T., and Mitcham, E. J. (2012). Factors involved in fruit calcium deficiency disorders. Hortic. Rev. (Am. Soc. Hortic. Sci). 40, 107-14doi:10.1002/9781118351871.ch3.

De Freitas,S.T., Amarante, C.V.T., Labavitch, J.M. and Mitcham. E. (2010.) Cellular approach to understand bitter pit development in apple fruit. Postharvest Biol. Tech. 57:6-13. 
Drake, M., Weeks, W.M., Baker, J.H., Field, D.L. Olanyk, G.W. (1966). Bitter pit as related to calcium level in Baldwin apple fruit and leaves. Proc. Amer. Soc. hort.Sci., 89, 23-

Dražeta, L., Lang, A., Hall, A. J., Volz, R. K., and Jameson, P. E. (2004). Causes and effects of changes in xylem functionality in apple fruit. Ann. Bot. 93, 375-382. doi:10.1093/aob/mch040.

Faust, M., and Shear, C. B. (1968). Corking Disorders of Apples: A Physiological and Biochemical Review. Bot. Rev. 34, 441-469. doi:10.2307/4353760.

Ferguson, I. B., and Watkins, C. B. (1989). Bitter pit in apple fruit. Hortic. Rev. (Am. Soc. Hortic. Sci). 11, 289-355. doi:10.1002/9781118060841.

Ferguson, I. B., and Watkins, C. B. (1992). Crop Load Affects Mineral Concentrations and Incidence of Bitter Pit in “Cox” s Orange Pippin’ Apple Fruit. J. Am. Soc. Hortic. Sci. 117, 373-376.

Fernández-Fernández, F., Antanaviciute, L., van Dyk, M. M., Tobutt, K. R., Evans, K. M., Rees, D. J. G., et al. (2012). A genetic linkage map of an apple rootstock progeny anchored to the Malus genome sequence. Tree Genet. Genomes 8, 991-1002. doi:10.1007/s11295-012-0478-7.

Fernández-Fernández, F., Evans, K. M., Clarke, J. B., Govan, C. L., James, C. M., Marič, S., et al. (2008). Development of an STS map of an interspecific progeny of Malus. Tree Genet. Genomes 4, 469-479. doi:10.1007/s11295-007-0124-y.

Fidler, J. C., Wilkinson, B.G., Edney, K.L. Sharples, R.O. (1973). The biology of apple and pear storage. Available at: http://agris.fao.org/agris-search/search.do?recordID=US201300517914 [Accessed October 3, 2017].

Franková, L., and Fry, S. C. (2013). Biochemistry and physiological roles of enzymes that "cut and paste" plant cell-wall polysaccharides. J. Exp. Bot. 64, 3519-3550. doi:10.1093/jxb/ert201.

Gilroy, S., Read, N. D., and Trewavas, A. J. (1990). Elevation of cytoplasmic calcium by caged calcium or caged inositol trisphosphate initiates stomatal closure. Nature 346, 769-771. doi:10.1038/346769a0.

Gullfot, F., Ibatullin, F. M., Sundqvist, G., Davies, G. J., and Brumer, H. (2009). Functional characterization of xyloglucan glycosynthases from GH7, GH12, and GH16 scaffolds. Biomacromolecules 10, 1782-1788. doi:10.1021/bm900215p.

Hewett, E. W., and Watkins, C. B. (1991). Bitter Pit Control by Sprays and Vacuum Infiltration of Calcium in “Cox"s Orange Pippin' Apples. The Society Available at: http://hortsci.ashspublications.org/content/26/3/284.abstract [Accessed November 16, 2017].

Hirschi, K. D. (2004). The Calcium Conundrum. Both Versatile Nutrient and Specific Signal. PLANT 
Physiol. 136, 2438-2442. doi:10.1104/pp.104.046490.

Ho, M. W., Kaetzel, M. A., Armstrong, D. L., and Shears, S. B. (2001). Regulation of a human chloride channel. a paradigm for integrating input from calcium, type ii calmodulin-dependent protein kinase, and inositol 3,4,5,6-tetrakisphosphate. J. Biol. Chem. 276, 18673-80. doi:10.1074/jbc.M101128200.

Ho, M. W. Y., and Shears, S. B. (2002). "Regulation of calcium-activated chloride channels by inositol 3,4,5,6 tetrakisphosphate," in, 345-363. doi:10.1016/S1063-5823(02)53041-6.

Hocking, B., Tyerman, S. D., Burton, R. A., and Gilliham, M. (2016). Fruit Calcium: Transport and Physiology. Front. Plant Sci. 7, 1-17. doi:10.3389/fpls.2016.00569.

Hoffman, M., Jia, Z., Peña, M. J., Cash, M., Harper, A., Blackburn, A. R., et al. (2005). Structural analysis of xyloglucans in the primary cell walls of plants in the subclass Asteridae. Carbohydr. Res. 340, 1826-1840. doi:10.1016/j.carres.2005.04.016.

Konrad, K. R., Wudick, M. M., and Feijó, J. A. (2011). Calcium regulation of tip growth: New genes for old mechanisms. Curr. Opin. Plant Biol. 14, 721-730. doi:10.1016/j.pbi.2011.09.005.

Korban, S., and Swiader, J. (1984). Genetic and nutritional status in bitter pit resistant and bitter pit susceptible apple malus domestica seedlings. J. Am. Soc. Hortic. Sci. 109, 428-432. Available at: https://eurekamag.com/research/005/512/005512179.php [Accessed August 2, 2017].

Kumar, S., Garrick, D. J., Bink, M. C., Whitworth, C., Chagné, D., and Volz, R. K. (2013). Novel genomic approaches unravel genetic architecture of complex traits in apple. BMC Genomics 14, 393. doi:10.1186/1471-2164-14-393.

Lampugnani, E. R., Moller, I. E., Cassin, A., Jones, D. F., Koh, P. L., Ratnayake, S., et al. (2013). In Vitro Grown Pollen Tubes of Nicotiana alata Actively Synthesise a Fucosylated Xyloglucan. PLoS One 8, 1-10. doi:10.1371/journal.pone.0077140.

Langmead, B., and Salzberg, S. L. (2012). Fast gapped-read alignment with Bowtie 2. Nat. Methods 9, 357-9. doi:10.1038/nmeth.1923.

Liu, L., Paulitz, J., and Pauly, M. (2015). The presence of fucogalactoxyloglucan and its synthesis in rice indicates conserved functional importance in plants. Plant Physiol 168, 549-560. doi:10.1104/pp.15.00441.

Livak, K. J., and Schmittgen, T. D. (2001). Analysis of relative gene expression data using real-time quantitative PCR and. Methods 25, 402-408. doi:10.1006/meth.2001.1262.

Longhi, S., Moretto, M., Viola, R., Velasco, R., and Costa, F. (2012). Comprehensive QTL mapping 
survey dissects the complex fruit texture physiology in apple (Malus x domestica Borkh.). $J$. Exp. Bot. 63, 1107-1121. doi:10.1093/jxb/err326.

Mathews, S. (2009). Phylogenetic relationships among seed plants: Persistent questions and the limits of molecular data. Am. J. Bot. 96, 228-236. doi:10.3732/ajb.0800178.

Miqueloto, A., Amarante, C. V. T. do, Steffens, C. A., dos Santos, A., and Mitcham, E. (2014). Relationship between xylem functionality, calcium content and the incidence of bitter pit in apple fruit. Sci. Hortic. (Amsterdam). 165, 319-323. doi:10.1016/j.scienta.2013.11.029.

Mitchell, J., Wang, X., Zhang, G., Gentzsch, M., Nelson, D. J., and Shears, S. B. (2008). An Expanded Biological Repertoire for Ins(3,4,5,6)P4 through its Modulation of ClC-3 Function. Curr. Biol. 18, 1600-1605. doi:10.1016/j.cub.2008.08.073.

Montanaro, G., Dichio, B., Lang, A., Mininni, A. N., and Xiloyannis, C. (2015). Fruit calcium accumulation coupled and uncoupled from its transpiration in kiwifruit. J. Plant Physiol. 181, 67-74. doi:10.1016/j.jplph.2015.04.004.

Morris, E. R., Powell, D. A., Gidley, M. J., and Rees, D. A. (1982). Conformations and interactions of pectins. I. Polymorphism between gel and solid states of calcium polygalacturonate. J. Mol. Biol. 155, 507-516. doi:10.1016/0022-2836(82)90484-3.

Ng, J. K., Schröder, R., Sutherland, P. W., Hallett, I. C., Hall, M. I., Prakash, R., et al. (2013). Cell wall structures leading to cultivar differences in softening rates develop early during apple (Malus x domestica) fruit growth. BMC Plant Biol. 13, 183. doi:10.1186/1471-2229-13-183.

Obel, N., Erben, V., Schwarz, T., Kühnel, S., Fodor, A., and Pauly, M. (2009). Microanalysis of plant cell wall polysaccharides. Mol. Plant 2, 922-932. doi:10.1093/mp/ssp046.

Padmarasu, S., Sargent, D. J., Jaensch, M., Kellerhals, M., Tartarini, S., Velasco, R., et al. (2014). Fine-mapping of the apple scab resistance locus Rvi12 ( Vb) derived from ???Hansen???s baccata \#2??? Mol. Breed. 34, 2119-2129. doi:10.1007/s11032-014-0167-3.

Peña, M. J., Darvill, A. G., Eberhard, S., York, W. S., and O’Neill, M. A. (2008). Moss and liverwort xyloglucans contain galacturonic acid and are structurally distinct from the xyloglucans synthesized by hornworts and vascular plants. Glycobiology 18, 891-904. doi:10.1093/glycob/cwn078.

Perring, M. A. (1985). Redistribution of Minerals in Apple Fruit During Storage : Effects of Late Summer Pruning, Calcium Sprays and Low Temperature Breakdown. 333-342.

Plieth, C. (2001). Plant calcium signaling and monitoring: pros and cons and recent experimental 
approaches.

Protoplasma

218 ,

$1-23$.

Available

at:

http://www.ncbi.nlm.nih.gov/pubmed/11732314 [Accessed October 3, 2017].

Poovaiah, B. W., and Leopold, A. C. (1973). Deferral of leaf senescence with calcium. Plant Physiol. 52, 236-9. doi:10.1104/PP.52.3.236.

Prinja, J. (1989). The effects of high CO2 pre-storage treatments and rate of establishment of controlled atmosphere conditions on bitter pit and bruise susceptibility of "Bramley"s Seedling' apples. J. Hortic. Sci. 64, 533-539. doi:10.1080/14620316.1989.11515988.

Ralet, M. C., Bonnin, E., and Thibault, J. F. (2001). Chromatographic study of highly methoxylated lime pectins deesterified by different pectin methyl-esterases. J. Chromatogr. B Biomed. Sci. Appl. 753, 157-166. doi:10.1016/S0378-4347(00)00500-4.

Sargent, D. J., Passey, T., Surbanovski, N., Lopez Girona, E., Kuchta, P., Davik, J., et al. (2012). A microsatellite linkage map for the cultivated strawberry (Fragaria?? ananassa) suggests extensive regions of homozygosity in the genome that may have resulted from breeding and selection. Theor. Appl. Genet. 124, 1229-1240. doi:10.1007/s00122-011-1782-6.

Schultink, A., Liu, L., Zhu, L., and Pauly, M. (2014). Structural diversity and function of xyloglucan sidechain substituents. Plants 3, 526-542. doi:10.3390/plants3040526.

Silfverberg-Dilworth, E., Matasci, C. L., Van de Weg, W. E., Van Kaauwen, M. P. W., Walser, M., Kodde, L. P., et al. (2006). Microsatellite markers spanning the apple (Malus x domestica Borkh.) genome. Tree Genet. Genomes 2, 202-224. doi:10.1007/s11295-006-0045-1.

Smock, R., and Neubert, A. (1950). Apples and apple products. New York ;London: Interscience Publisher $\quad$ INC. ;Interscience Publishers LTD. Available at: http://www.worldcat.org/title/apples-and-apple-products/oclc/750786103 [Accessed August 2, 2017].

Tibbits, C. W., MacDougall, A. J., and Ring, S. G. (1998). Calcium binding and swelling behaviour of a high methoxyl pectin gel. Carbohydr. Res. 310, 101-107. doi:10.1016/S00086215(98)00172-4.

Tomala, K., and Soska, A. (2004). Effects of calcium and / or phosphorus sprays with different commercial preparations on quality and storability of Šampion apples. Hortic. Sci. 2004, 12-16.

Untergasser, A., Cutcutache, I., Koressaar, T., Ye, J., Faircloth, B. C., Remm, M., et al. (2012). Primer3--new capabilities and interfaces. Nucleic Acids Res. 40, e115. doi:10.1093/nar/gks596.

Van Ooijen, J. (2009). MapQTL 6, Software for the mapping of quantitative trait loci in experimental 
populations of diploid species.

Van Ooijen, J. W. (2006). JoinMap ${ }^{\circledR}$ 4, Software for the calculation of genetic linkage maps in experimental populations. Kyazma BV, Wageningen 33, 10-1371. Available at: https://www.scienceopen.com/document?vid=baa76c8c-fb55-4c13-a6ca-24c71002ab5a [Accessed October 3, 2017].

Velasco, R., Zharkikh, A., Affourtit, J., Dhingra, A., Cestaro, A., Kalyanaraman, A., et al. (2010). The genome of the domesticated apple (Malus x domestica Borkh.). Nat Genet 42, 833-839. doi:10.1038/ng.654.

Volz, R. K., Alspach, P. A., Fletcher, D. J., and Ferguson, I. B. (2006). Genetic variation in bitter pit and fruit calcium concentrations within a diverse apple germplasm collection. Euphytica 149, 1-10. doi:10.1007/s10681-005-9000-8.

Voorrips, R. E. (2002). MapChart: software for the graphical presentation of linkage maps and QTLs. J. Hered. 93, 77-78. doi:10.1093/jhered/93.1.77.

White, P. J. (2000). Calcium channels in higher plants. Biochim. Biophys. Acta-Biomembr. 1465, 171-189. doi:10.1016/S0005-2736(00)00137-1.

White, P. J., and Broadley, M. R. (2003). Calcium in plants. Ann. Bot. 92, 487-511. doi:10.1093/aob/mcg164.

Willats, W. G., McCartney, L., Mackie, W., and Knox, J. P. (2001). Pectin: cell biology and prospects for functional analysis. Plant Mol. Biol. 47, 9-27. Available at: http://www.ncbi.nlm.nih.gov/pubmed/11554482 [Accessed October 3, 2017].

Zhang, C., Halsey, L. E., and Szymanski, D. B. (2011). The development and geometry of shape change in Arabidopsis thaliana cotyledon pavement cells. BMC Plant Biol. 11, 27. doi:10.1186/1471-2229-11-27.

Zhang, H. N., Zhou, J. G., Qiu, Q. Y., Ren, J. L., and Guan, Y. Y. (2006). ClC-3 chloride channel prevents apoptosis induced by thapsigargin in PC12 cells. Apoptosis 11, 327-336. doi:10.1007/s10495-006-3980-2.

Zupan, A., Mikulic-Petkovsek, M., Cunja, V., Stampar, F., and Veberic, R. (2013). Comparison of phenolic composition of healthy apple tissues and tissues affected by bitter pit. J. Agric. Food Chem. 61, 12066-12071. doi:10.1021/jf404087f. 
Table 1 - RNA sequencing and read mappings statistics. For each RNA library, number of obtained Illumina 101-bps single-end reads and number/percentage of reads mapped to predicted apple genes (Malus_x_domestica.v1.0.consensus_CDS.fa) were reported.

\begin{tabular}{lccc}
\hline Sample ID & Number of raw reads & Number of reads mapped to genes & Percentage of reads mapped to genes \\
\hline Non-susceptible stage 1 & $43,693,302$ & $29,688,729$ & $67.9 \%$ \\
Non-susceptible stage 7 & $43,369,657$ & $29,099,891$ & $67.1 \%$ \\
Susceptible stage 1 & $47,381,363$ & $32,387,496$ & $68.4 \%$ \\
Susceptible stage 7 & $51,088,161$ & $34,695,047$ & $67.9 \%$ \\
\hline
\end{tabular}

Table 2 - 13 candidate genes differentially expressed in the LG16 QTL region and validated by RT-qPCR. For each gene we reported position, predicted function, amplicon length and sequence of primers used for RT-qPCR.

\begin{tabular}{|c|c|c|c|c|c|c|c|}
\hline Gene ID & Primers & Chr & $\begin{array}{l}\text { Position } \\
\text { on chr }\end{array}$ & $\begin{array}{c}\text { Predicted } \\
\text { function/activity }\end{array}$ & $\begin{array}{c}\text { Amplicon } \\
\text { length }\end{array}$ & Forward primer sequence & Reverse primer sequence \\
\hline MDP0000137803 & HK5 & $\operatorname{chr} 16$ & 365,838 & Histidine kinase & 104 & GCATTGCATGTTGGCCAC & ACTGCCTTGGCCTGTTTCTT \\
\hline MDP0000186069 & CE2 & chr16 & 465,759 & Cysteine endopeptidase & 105 & CTCAAGCCACGTCCCGCA & TTTCCTTCTCTGCGCTGTCC \\
\hline MDP0000071852 & LT3 & chr16 & 851,804 & $\begin{array}{l}\text { Plant lipid transfer } \\
\text { serine/threonine kinase }\end{array}$ & 101 & GCCTCTGCCAGTATGTGAAGA & GCATGTGGGGAATGGGGAA \\
\hline MDP0000475514 & STK1 & $\operatorname{chr} 16$ & 939,438 & $\begin{array}{l}\text { activity } \\
\text { transcription repressor }\end{array}$ & 104 & AGGAAGAAGGAACATCGGCG & TCTGCAGACCAAGCTCTTCG \\
\hline MDP0000376284 & TRR1 & chr16 & $1,530,246$ & activity & 103 & GGATGAGTGCTTCGATGGCT & AACGGTGTTTTCGGTGGAGA \\
\hline MDP0000612469 & ZB2 & $\operatorname{chr} 16$ & $1,794,944$ & Zinc ion binding & 106 & CGCCTAGCTCCACCAAGAAG & CGCCACGATCACTATCCGAG \\
\hline MDP0000612477 & HB2 & $\operatorname{chr} 16$ & $1,827,059$ & Heam-binding & 114 & ACACAATCACGCTGACAGGT & CGATTCCAGGGCATTCGGAT \\
\hline MDP0000263725 & KIN1 & chr16 & $2,294,285$ & Kinase activity & 115 & TGCCCGATGTATCTGCTGAC & AGTTGAGTCCTTGGAGCAGC \\
\hline MDP0000177891 & $\mathrm{OGH} 2$ & $\operatorname{chr} 16$ & $2,566,888$ & $\begin{array}{l}\text { O-glycosyl hydrolase } \\
\text { Glycosyl transferase }\end{array}$ & 114 & ССТСССТCAAGCCTTGGAAG & TGCTTCACCCTGTCACCAAA \\
\hline MDP0000529420 & GTA2 & $\operatorname{chr} 16$ & $2,857,543$ & activity & 108 & CTTCACCAGGGATGCCGAAA & CCCCATTCACAGTCGGATGT \\
\hline MDP0000300083 & GT1 & $\operatorname{chr} 16$ & $2,880,162$ & Glycosyl transferase & 110 & TCAGGGATGCCGAAACAGAA & TTACCAACACGTCGCACAGA \\
\hline MDP0000199110 & DNAB7 & chr16 & $3,128,389$ & DNA binding & 103 & AACAAGCACGGTCTCAGGAG & CACCCTCACCGTTGATCTCA \\
\hline MDP0000161881 & TF3 & chr16 & $3,381,593$ & Transcription factor & 107 & GCAGAAATGGTCAAGGTTAGGG & TGAAGAAGGCCATGAAGATGCA \\
\hline
\end{tabular}

